\title{
Electronic Load Controller for Self Exited Induction Generator Using Fuzzy Logic Controller
}

\author{
Yellaiah.Ponnam ${ }^{1,}$ P.Ravi Kumar ${ }^{2,}$ V.Varun Kumar $^{3}$ \\ Asst.Professor Dept. of EEE Sri Indu College of Engineering \&Technology(Autonomous), Affiliated to JNTU \\ Hyderabad, India \\ Pursuing B.Tech Dept. of EEE Gurunanak Institutions Technical Campus(formerly GuruNanak Engineering \\ College) Hyderabad, India \\ Assoc.Professor Dept. of EEE GuruNanak Institutions Technical Campus(formerly GuruNanak Engineering \\ College) Hyderabad, India
}

\begin{abstract}
This paper deals with the electronic load controller for self exited induction generator using fuzzy logic controller. The self-excited induction generators (SEIGs) are considered to be well suited for generating electricity by means of conventional energy sources and for supplying electrical energy in remote and rural areas. Induction generators have many advantages such as cost, reduced maintenance, rugged, and simple construction, brushless rotor (squirrel cage). A three phase induction generator can be operated on a delta connection for supplying single phase loads. The main disadvantage of SEIG has is that it poor voltage regulation, and its value depends on the prime mover speed, capacitance, load current and power factor of the load. The electronic load controller (ELC) can be used for maintaining constant voltage and frequency of SEIG with variable consumer load driven by constant prime mover. This paper presents the simulation design and implementation of ELC using fuzzy logic method for an SEIG feeding single-phase load. The ELC consist of a rectifier, IGBT as a chopper switch, PI controller, voltage sensor, and resistive dump load in which power consumption was varied through the duty cycle of the chopper. However an ELC consist of electronics system, in general, has complex nonlinear model with parameter variation problem, and the control need to be very fast. The fuzzy logic based controller gives nonlinear control with fast response and virtually no overshoot. The simulation of ELC for self exited induction generator is carried out on MATLAB/SIMULINK. By this proposed ELC using FLC for SEIG we can maintain the constant voltage and frequency of SEIG with variable consumer load.
\end{abstract}

Keywords - Electronic load controller (ELC), Self excited induction generator (SEIG), Fuzzy logic controller.

\section{Introduction}

Recently, most of the electricity is generated making use of fossil fuels (coal, oil, and natural gas). These fossil fuels are limited and will run out in the future. Fossil fuels are a nonrenewable energy source and they have continuously degraded the environmental conditions. In such a situation researchers are forced to make effort to make use of new and renewable energy sources in an economical and safe way. Among electrical generation using the renewable sources, micro hydro generation systems are an attractive alternative for remote locations where an consider economical, robust and require minimal maintenance and are likely to be managed by un- skilled operators, because they are usually installed remote from any maintenance facilities.

The squirrel cage induction machine with capacitive self excitation, known as self-excited induction generators (SEIGs) are considered as an alternative to the well-developed synchronous generators. Induction generators are widely used for micro-hydro powered electric generation, especially in remote and isolated areas, because they do not need an external power supply to produce the excitation magnetic field. Furthermore, induction generators have more advantages such as low cost, reduced maintenance, rugged and simple construction, brushless rotor (squirrel cage), good over-speed capability, and inherent protraction against short circuit [1] .Keeping the voltage and frequency of SEIG constant in spite of the change in load, can be done by regulating the capacitance value or by controlling the speed of the prime movers. One alternative for supplying single phase loads widely used in remote and rural areas is using three-phase induction generator. It is used to supply the single phase loads by using the connection delta. If the induction generator is used to supply single phase with a constant load, the ELC could be applied to maintain constant power output SEIG, for this purpose the dump load must be connected in parallel with the consumer load so that the total power load is generated by the SEIG is constant. The amount of power that flowing into the dump load is controlled by the electronic load controller (ELC) [4]-[5]. 
Various controllers for SEIG have been reported in literature. T.Chandra Sekhar et.al. [2] Proposed different voltage regulation schemes such as power electronic controller, electronic load controller and magnetic amplifier (saturable core reactor). Bhim Singh et.al [5] has been developed an ELC for two winding single phase SEIG. Juan M.Ramirez et.al [3] proposed an ELC with anti parallel insulated-gate bipolar transistor (IGBT) switches are used to control dump load connection and disconnection. D.K.Palwalia et.al [6] present design and implementation of Digital Signal Processor (DSP) based induction generator controller (IGC) for single phase SEIG. Sarsing Gao et al [1] present analysis and the design of a microcontroller (PIC 18F252) based SEIG-ELC. A PI controller is used to provide proper control without steady state errors or instability.

This paper presents the simulation design and implementation of Electronic Load Controller (ELC) for a Self Excited Induction Generator (SEIG) using Fuzzy Logic Controller. The SEIG using three phase induction generator feeding single phase loads. In addition to the PI controller we are using FLC. The mains reasons of using fuzzy logic controller to gives nonlinear control with fast response and virtually no overshoot. The proposed ELC will be simulated under variable consumer load and resistive load as the dump load in ELC.

\section{System Description}

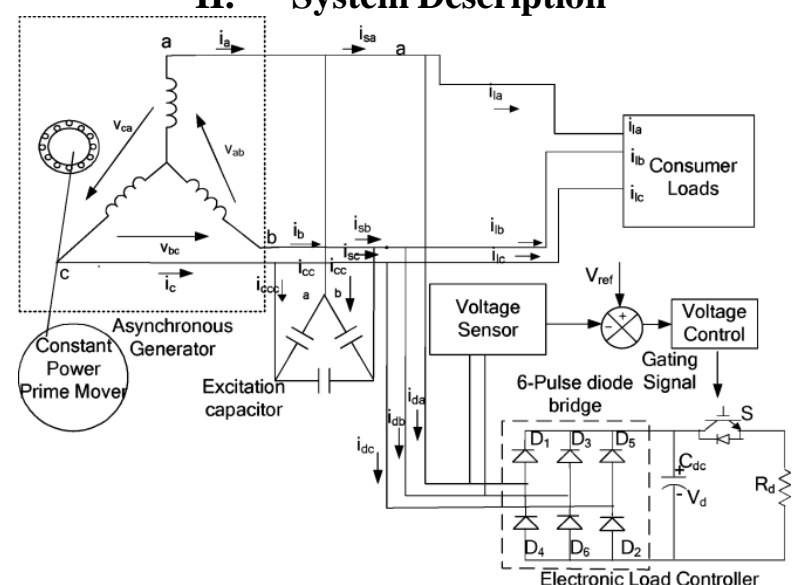

Fig.1 SEIG system configuration control strategy of a chopper switch in a six - pulse diode bridge ELC using FLC.

Fig.1 shows the isolated Pico hydro generating system that consists of an SEIG, excitation capacitor, consumer loads, and conventional ELC (six-pulse diode rectifier along with the chopper). The diode bridge is used to convert ac terminal voltage of SEIG to dc voltage. The output dc voltage has the ripples, which should be filtered, and therefore, a filtering capacitor is used to smoothen the dc voltage. An insulated gate bipolar junction transistor (IGBT) is used as a chopper switch providing the variable dc voltage across the auxiliary load. When the chopper is switched oN, the current flows through its auxiliary load and consume the difference power (difference of generated power and consumer load power) that results in a constant load on the SEIG, and hence, constant voltage and frequency at the varying consumer loads. The duty cycle of the chopper is varied by an analog-controller-based proportional-integral (PI) regulator and Fuzzy Logic Controller. The sensed terminal voltage is compared with reference voltage and error signal is processed through PI controller. The output of PI controller is given to fuzzy logic controller and it generates outputs and these are compared with fixed frequency saw tooth wave to generate the varying duty cycle switching signal for the chopper switch. According to the principle of operation of the system, the suitable value of capacitors is connected to generate rated voltage at desired power [9]. The input power of the SEIG is held constant at varying consumer loads. Thus, SEIG feeds two loads (consumer load + ELC) in parallel such that the total power is constant

$$
P_{G E N}=P_{E L C}+P_{L O A D}
$$

Where $P_{G E N}$ is generated power by the SEIG (which should be kept constant), $P_{L O A D}$ is consumed power by consumers, and $P_{E L C}$ is the power absorbed by the ELC.

\section{Fuzzy Logic Controller}

A fuzzy logic controller consists of four main components as fuzzification, rule base, inference mechanism and defuzzification. The fuzzification converts its inputs into fuzzy values with membership functions in the form of triangle, trapezoid, bell or other appropriate forms expressed by the fuzzy linguistic variables. The rule base contains the expert's linguistic descriptions expressed in the form of logical implications such as IF $\mathrm{x}$ is positive THEN $\mathrm{y}$ is big. The inference mechanism evaluates fuzzy information to 
activate and apply control rules. The defuzzification that uses methods such as centre of gravity, maximum and weighted mean converts the inference mechanism into the crisp values applied to the actual system.

The proposed SEIG based on ELC using FLC. In this FLC having two inputs and one output of the fuzzy controller. The first input is the error between reference value that is desired output value and generator output value. The second input is the derivative of the error. The inputs are given by:

$$
\begin{aligned}
& \mathrm{e}(\mathrm{k})=\mathrm{r}(\mathrm{k})-\mathrm{y}(\mathrm{k}) \\
& \Delta \mathrm{e}(\mathrm{k})=\mathrm{e}(\mathrm{k})-\mathrm{e}(\mathrm{k}-1)
\end{aligned}
$$

The design of the fuzzy controller depends on information about the system behavior or experience of a human expert. The fuzzification stage is determined by the choice of the range, shape and number of the membership functions. The input membership functions for the error and the delta error to the fuzzy controller, the positioning universe was divided into seven domains which are negative big (NB), negative medium (NM), negative small (NS), zero (Z), positive small (PS), positive medium (PM), and positive big (PB). The output membership functions are chosen to be non uniformly distributed seven singletons functions. The output membership function processed by the fuzzy logic algorithm produces the PWM singletons taken as output assignments for the control dump load.

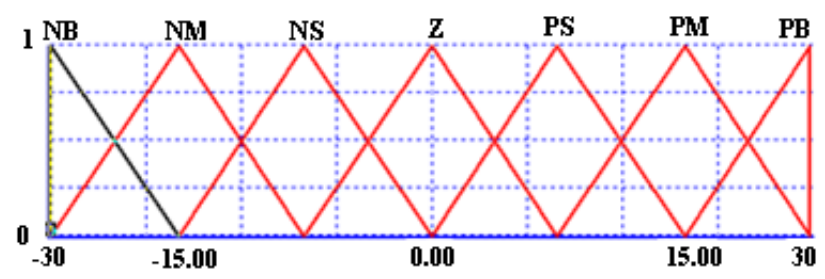

Fig.2 Membership functions of error and the delta Error

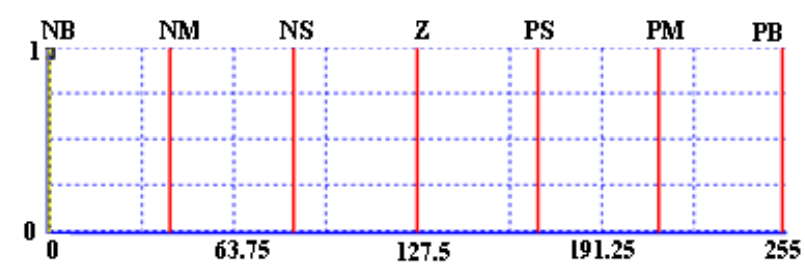

Fig.3 Membership functions output

The set of rules for fuzzy controller is shown in Table I.

\begin{tabular}{|c|c|c|c|c|c|c|c|}
\hline $\begin{array}{c}\text { Error } \\
\text { dError }\end{array}$ & NB & NM & NS & Z & PS & PM & PB \\
\hline NB & PB & PB & PM & PS & PS & Z & NS \\
\hline NM & PB & PM & PM & PS & Z & NS & NM \\
\hline NS & PB & PM & PS & Z & Z & NS & NM \\
\hline Z & PB & PM & PS & Z & NS & NM & NB \\
\hline PS & PM & PS & Z & Z & NS & NM & NB \\
\hline PM & PM & PS & Z & NS & NM & NM & NB \\
\hline PB & PS & Z & NS & NS & NM & NB & NB \\
\hline
\end{tabular}

Table I. Fuzzy Associative Memories (FAM)

\section{Matlab Based Modeling}

A $7.5 \mathrm{~kW}, 415 \mathrm{~V}, 50 \mathrm{~Hz}$ asynchronous machine is used as a SEIG and the ELC is modeled using available power electronics block set like diode bridge rectifier and a chopper with an auxiliary resistive load. For voltage control we are using PI controller and Fuzzy Logic Controller.

Simulation is carried out in MATLAB/SIMULINK version of 7.9 at discrete step of $1 \mathrm{E}-6$. Detailed simulation of ELC for self excited induction generator using FLC is given in following sections. 


\section{Simulation Study}

Here, transient waveforms of the generator voltage $\left(V_{a b c}\right)$, generator current ( $\left.i_{\mathrm{abc}}\right)$, capacitor currents $\left(i_{\mathrm{cabc}}\right)$, consumer load current $(i \mathrm{labc})$, ELC current $\left(i_{\mathrm{da}}, i \mathrm{db}, i \mathrm{dc}\right)$, rms value of the generated voltage $\left(v_{\mathrm{rms}}\right)$, frequency $(f)$, speed of the generator $(w \mathrm{~g})$, variation in the load power $\left(P_{\text {load }}\right)$, ELC power $\left(P_{\mathrm{ELC}}\right)$, and generated power $\left(P_{\mathrm{gen}}\right)$ are given under the sudden application and removal of the consumer loads for ELC using FLC in Fig.4 and 5 respectively.

\section{Performance of Electronic Load Controller using FLC.}

Fig. 4 shows the different transient waveforms of SEIG with conventional ELC using six-pulse diode bridge rectifier. Here, the value of the capacitor is selected for generating the rated RMS voltage (415 V) at rated load $(7.5 \mathrm{~kW})$. Initially, the consumer load is OFF and the ELC is consuming full $7.5 \mathrm{~kW}$ power to an auxiliary load.

At $2 \mathrm{~s}$, a consumer load of around $5 \mathrm{~kW}$ is switched $\mathrm{ON}$ and it is observed that to control the constant power at the generator terminal, the current drawn by ELC is reduced, while on removal of consumer load at $2.3 \mathrm{~s}$, it is again increased. Because of using six-pulse bridge-rectifier-based ELC using FLC, the distortion in the generator voltage and current is observed, and the magnitude and frequency of the generated voltage are maintained constant. And generated power is also maintained constant throughout the operation of the machine with variable consumer load.

\section{Experimental Investigation}

In the experimental investigation, sensed terminal voltage of SEIG is compared with reference voltage and error signal is fed to the PI controller. The proportional and integral gains of the PI controller can be varied externally by means of having potentiometers. The error signal is fed to fuzzy control block through PI controller and FLC generates the outputs. This output of the PI controller and FLC is compared with the saw tooth carrier waveform. Frequency and magnitude of the saw tooth waveform are decided by the externally connected resistive and capacitive elements. The PI controller and PWM generator are available in a Pulse generator. The output stage of the PWM controller has two push-pull amplifiers, which gives two outputs, one with a duty cycle variation of $0-45 \%$ and the second with duty cycle variation of $50-95 \%$. For the chopper application, only a single output is needed with the duty cycle varying in the maximum possible range. The chopper has to be kept OFF when the SEIG is building up voltage and also when it is fully loaded with the consumer load. Figs. 4 and 5 demonstrate the simulation performance of proposed ELC using Fuzzy logic controller under dynamic conditions of load variations, respectively.
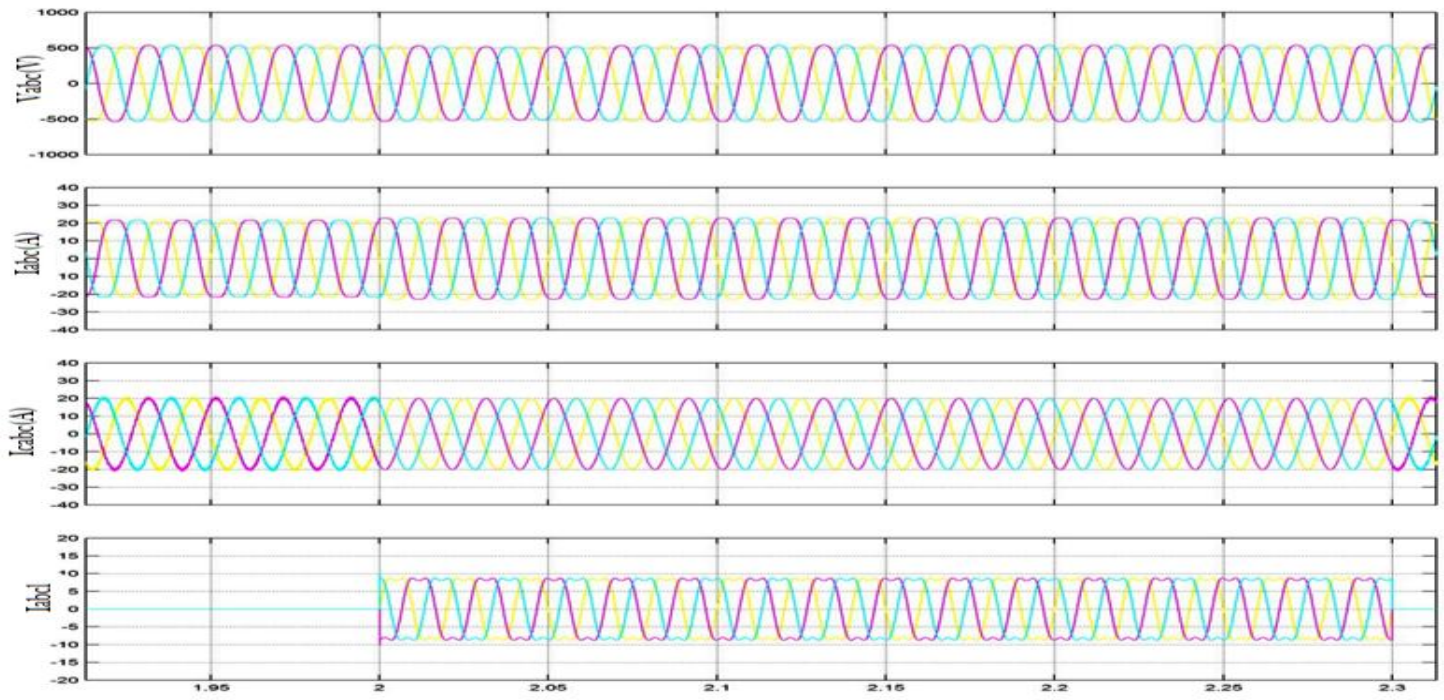

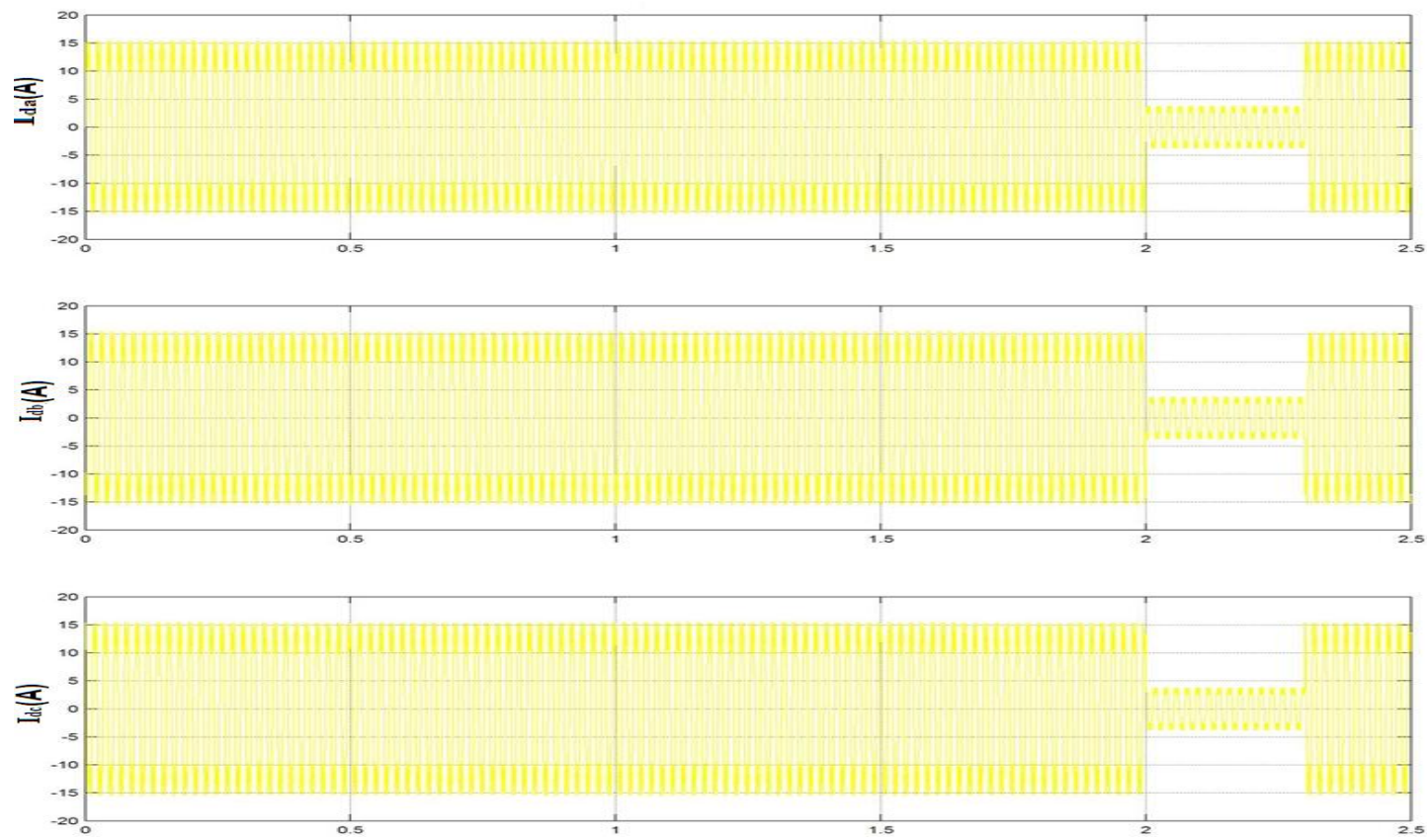

Fig.4 Simulation transient waveforms for generated voltage $\left(\mathrm{V}_{\mathrm{abc}}\right), \mathrm{I}_{\mathrm{abc}}, \mathrm{I}_{\mathrm{cabc}}, \mathrm{I}_{\mathrm{abcl}}$ and dump load currents $\left(\mathrm{I}_{\mathrm{da}}, \mathrm{I}_{\mathrm{db}}, \mathrm{I}_{\mathrm{dc})}\right.$ of SEIG based on ELC using FLC on application and removal consumer load.
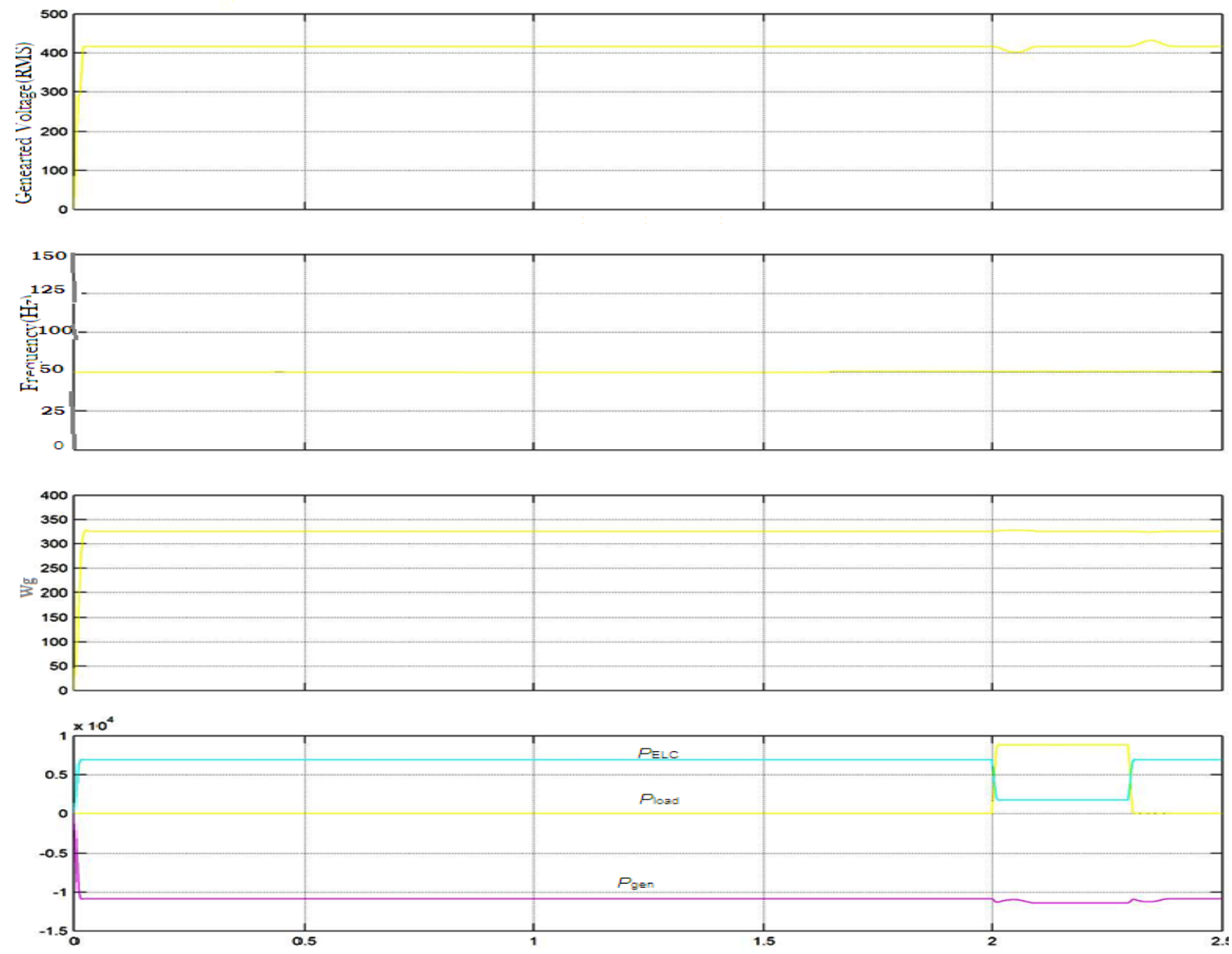

Fig.5 Simulation transient waveforms for generator RMS voltage. Frequency, generator speed and powers

$\left(\mathrm{P}_{\mathrm{ELC}}, \mathrm{P}_{\mathrm{LOAD}}\right.$ and $\mathrm{P}_{\mathrm{GEN}}$ and SEIG based on ELC using FLC on application and removal consumer load.

Fig. 4 and 5 shows the performance of SEIG with the ELC using FLC at sudden application and removal of the consumer load, respectively. Here, it is clearly demonstrated that when the consumer load is applied, the 
controller responds and current flowing through ELC is reduced to control total generated power at the generator terminal constant. Availability of the sufficient excitation capacitor keeps the constant voltage at the generator terminal. Here, an observation is made that because of the ELC using FLC the system response increases and overshoots in the system due to sudden change in load is reduced. Another observation is made that by using the FLC based ELC for SEIG the generator power, frequency and speed is maintained constant with variation of consumer load.

\section{Conclusion}

Electronic load controller for a self excited induction generator using fuzzy logic controller has been developed on the basis of simulation using standard software MATLAB. The FLC based ELC for SEIG has given constant power and constant frequency in the operation of self exited induction generator at varying consumer loads. And the system response is also fast compared to the ELC using PI controller and overshoots reduced by using fuzzy logic controller.

\section{References}

[1] R. C. Bansal, “Three-Phase Self-Excited Induction Generators: An Overview," IEEE Transactions on Energy Conversion, Vol. 20, No. 2, pp. 292-299 June 2005.

[2] Chandra, T.S., Bishnu, P.M., Voltage Regulators for Self Excited Induction Generator, IEEE Transactions on Energy Conversion,

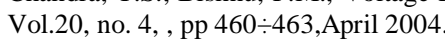

[3] Juan M. Ramirez and Emmanuel Torres M., "An electronic load controller for self excited induction generators" in IEEE PES General Meeting, June 24-28, 2007.

[4] Sarsing Gao, S. S. Murthy, G. Bhubaneswar, and M. Sree Lalitha Gayathri, "Design of a Microcontroller Based Electronic Load Controller for a Self Excited Induction Generator Supplying Single - Phase Loads," Journal of Power Electronics, Vol. 10, No.4, pp.444- 449, 2010

[5] Bhim Singh, S.S. Murthy \& Sushma Gupta ,"An Electronic Voltage and Frequency Controller for Single-Phase Self-Excited Induction Generators for Pico Hydro Applications",IEEE PEDS, pp 240-245,2005.

[6] Palwalia, D.K.; Singh, S.P.; , "Design and implementation of induction generator controller for single phase self excited induction generator," Industrial Electronics and Applications, 2008. ICIEA 2008. 3rd IEEE Conference on, vol., no., pp.400-404, 3-5 June 2008 .

[7] Bhim Singh, S.S. Murthy \& Sushma Gupta ,"An Electronic Voltage and Frequency Controller for Single-Phase Self-Excited Induction Generators for Pico Hydro Applications",IEEE PEDS, pp 240-245,2005.

[8] B. Singh, S. S. Murthy and S. Gupta, "Analysis and Implementation of an Electronic Load Controller for a Self- Excited Induction Generator," IEE Proceedings Generation Transmission and Distribution, Vol. 151, No.1, pp. 51-60,January 2004.

[9] B. Singh, S. S. Murthy, and S. Gupta, "STATCOM based voltage regulator for isolated asynchronous generator feeding non-linear loads," IEEE Trans. Ind. Electron., vol. 53, no. 5, pp. 1437-1452, Oct. 2006.

\section{ABOUT AUTHORS:}

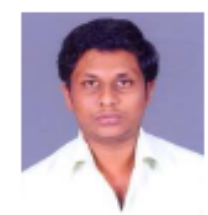

Ponnam.Yellaiah, Asst.Professor

Received M.Tech degree in Control Systems in Dept. of Electrical and Electronics Engineering, JNTU Hyderabad. He is currently working as Asst. Professor in EEE Department of Sri Indu College of Engineering \&Technology(Autonomous) ,Hyderabad, His is doing currently research in control system, Power electronics, FACTS and PLCs

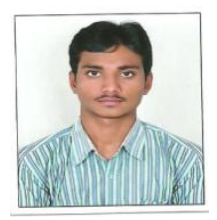

\section{Ravi Kumar. Pendli, Pursuing B.Tech}

Pursuing B.Tech degree in Electrical and Electronics Engineering from Guru Nanak Institutions Technical Campus (formerly Guru Nanak Engineering College), JNTU Hyderabad. Area of interests include Power Systems Control Systems and Renewable Energy Systems.

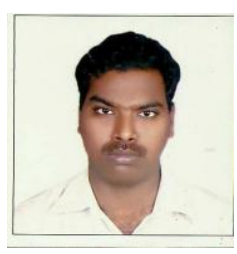

\section{Varun Kumar Vattikuti, Assoc. Professor}

Received M.Tech degree in Electrical Power Systems in Electrical and Electronics Engineering from the University of JNTU Hyderabad. He is currently working as Assoc.Professor in EEE Department in Guru Nanak Institutions Technical Campus (Formerly Guru Nanak Engineering College), Hyderabad, His currently research interests include control system, Power electronics, 